\title{
Comment on women in surgery: little change in gender equality in Japanese medical societies over the past 3 years
}

\author{
Hilary Sanfey
}

Received: 19 December 2012/ Accepted: 21 January 2013/Published online: 22 June 2013

(C) Springer Japan 2013

Dr. Tomizawa has presented an eloquent review of the gender discrepancies that exist in Japan today [1]. She notes that gender equality in the member societies of the JAMS continues to lag behind that of other industrialized nations. The Japanese Association of Women Surgeons, of which Dr. Tomizawa is the president, has led the way in developing policies for change. In the USA, change has also been slow: Currently, fewer than $5 \%$ of surgery department chairs are women. Moreover, women account for only $7 \%$ of full professors of surgery versus $13 \%$ of full professors of medicine. The American College of Surgeons has had two women presidents in 100 years but the Royal Colleges of Surgeons in Ireland, of England, Glasgow and Edinburgh have only had one woman president in their collective 1,000-year history!

The reasons for these differences are multifactorial and include competing priorities for women making it more difficult to compete on an equal footing, particularly in the junior faculty years; implicit or unconscious bias, precluding women from being offered the opportunity to acquire the skills to become competitive; and occasionally, blatant discrimination. Since almost $40 \%$ of the residents entering general surgery now are women, it is important to explore why they are still less likely than their male counterparts to receive tenure and to be underrepresented in higher faculty ranks and in leadership positions. Thus, those of us fortunate enough to have achieved success in our profession have an obligation to offer mentorship and support to the women who come after us, so that our successors can also achieve their personal and professional goals.

Conflict of interest Hilary Sanfey has no conflict of interest.

\section{Reference}

1. Tomizawa Y. Women in surgery: little change in gender equality in Japanese medical societies over the past 3 years. Surg Today. 2012. doi:10.1007/s00595-012-0447-7.
H. Sanfey $(\bowtie)$

Department of Surgery, SIU School of Medicine,

PO Box 19638, Springfield, IL 62794, USA

e-mail: hsanfey@siumed.edu 